\title{
Application of probabilistic precipitation forecasts from a deterministic model towards increasing the lead-time of flash flood forecasts in South Africa
}

\author{
Eugene Poolman ${ }^{1 *}$, Hannes Rautenbach ${ }^{2}$ and Coleen Vogel ${ }^{2}$ \\ 'South African Weather Service, Pretoria 0001, South Africa \\ ${ }^{2}$ Department of Geography, Geoinformatics and Meteorology, University of Pretoria 0002, South Africa
}

\begin{abstract}
Flash floods are some of the most devastating weather-related hazards in South Africa. The South African Flash Flood Guidance (SAFFG) system is a hydro-meteorological modelling system that provides forecasts for the next 1 to $6 \mathrm{~h}$ of potential flash floods in support of the flash flood warning system of the South African Weather Service (SAWS). The aim of this paper is to investigate the increase in the lead-time of flash flood warnings of the SAFFG using probabilistic precipitation forecasts generated by the deterministic Unified Model (UM) from the United Kingdom Met Office and run by the South African Weather Service (SAWS). As a first step, calculations of bias-corrected, basin-averaged rainfall from the UM model are provided. An ensemble set of 30 adjacent basins is then identified as ensemble members for each basin (the target basin), from which probabilistic rainfall information is calculated for the target basin covering the extended forecast period. By comparing this probabilistic rainfall forecast with the expected Flash Flood Guidance (FFG) of each basin, an outlook of potential flash flooding is provided. The procedure is applied to a real flash flood event and the ensemble-based rainfall forecasts are verified against rainfall estimated by the SAFFG system. The approach described here is shown to be able to deal with the uncertainties associated with UM rainfall forecasts, particularly regarding location and onset-time of convection. The flash flood outlook for the 18 -h extended forecast period investigated was also able to capture the location of the flash flood event and showed its ability to provide additional lead-time for flash flood warnings to disaster managers.
\end{abstract}

Keywords: deterministic model ensembles, disasters, early warnings, flash floods, flash flood guidance, numerical weather prediction

\section{INTRODUCTION}

\section{The flash flood warning system}

The impact of weather on human livelihood is undisputed (Auld, 2008; ISDR, 2005a; ISDR, 2005b; Parry et al., 2008; Pelling, 2011). The atmosphere, while providing resources for life in the form of water, can become extremely hostile and violent in the form of hazards such as heavy rain, gales, thunderstorms or tropical cyclones. It is when these severe natural events impact negatively on humans and aggravate livelihood that it can become disastrous. An analysis of disasters in South Africa between 1900 and 2014, from the international disaster database hosted by the Centre for Research on the Epidemiology of Disasters (CRED), revealed that of all natural hazards occurring in South Africa, floods were more numerous ( $34 \%$ of the number of disasters), caused the most deaths and resulted in the most significant impact to people, their livelihoods and infrastructure (CRED, 2014).

The Inter-Governmental Panel on Climate Change (IPCC) Special Report on Managing the Risks of Extreme Events and Disasters issued in 2012 (IPCC, 2012) projected, with various levels of confidence, that climate change and climate variability could lead to changes in the frequency, intensity, spatial extent, duration and timing of extreme weather and climate

To whom all correspondence should be addressed

Tel: +27 12367 6001; e-mail: eugene.poolman@weathersa.co.za Received 14 February 2014; accepted in revised form 7 October 2014. events. South Africa will not be spared these possible changes and, though the annual total precipitation change is variable, heavy precipitation (that is the magnitude of the rainfall event) is expected to increase which could lead to an increase in flood events. As population numbers grow and increasing numbers of people settle in flood-prone areas or try to make a living in marginal regions, the risk of natural hazards becoming disasters increases (ISDR 2005a). This has motivated the call for more and improved early warning systems to contribute to enhanced resilience to changing climate and weather (IPCC, 2012).

Flash floods are neither strictly hydrological nor purely meteorological in nature. They are typical hydro-meteorological problems largely due to their nature as a hydrological hazard with a rapid response (within $6 \mathrm{~h}$ ) to a meteorological phenomenon (e.g. rainfall) (WMO, 2008; WMO, 2011; AMS, 2012). For this reason, the South African Weather Service (SAWS), operating a 24-h, 7 days a week monitoring service, takes the lead in issuing flash flood warnings in South Africa.

The general flash flood warning system of SAWS depends on a number of supporting systems and datasets, including rainfall forecasts from Numerical Weather Prediction (NWP) models, as well as radar and satellite information. Since October 2010, the South African Flash Flood Guidance (SAFFG) system provides additional information to weather forecasters, hydrologists and disaster managers in support of the flash flood warning system. Note that the SAFFG is the intellectual property of the Hydrologic Research Center (HRC), a non-profit public-benefit corporation based in San Diego, USA, and that the SAFFG was developed and implemented by HRC. 
One of the operational weaknesses of the SAFFG system as it has been implemented is that it is essentially a diagnostic system with a limited predictive ability of at most $6 \mathrm{~h}$. To provide a forecast for the next 1 to $6 \mathrm{~h}$ (nowcast) of flash flood threat, the same rainfall amounts and patterns estimated by the SAFFG system over the previous period (for example 6-h) are assumed to occur again over the next $6 \mathrm{~h}$ (i.e. persisted) over the same small basins. These persisted rainfall values are then compared with the Flash Flood Guidance (FFG) values to provide at most a 6 -h forecast of the potential flash flood threat. Such operations, however, do not allow disaster managers much lead-time to prepare appropriate reactions (Poolman, 2009), particularly if the catchment response time is less than the reaction time of disaster managers (Sene, 2008). In these situations additional lead-time becomes increasingly important. Extended lead-time is also important to develop 'what if?' scenarios for operational decision making. Since rainfall information is the key dynamical input into the SAFFG modelling system that affects the state of soil moisture and thus the eventual FFG value, rainfall forecasts could be used to extend the lead-time of flash flood warnings (Sene, 2008).

\section{Uncertainty in rainfall prediction}

Rainfall forecasting is one of the most difficult tasks in weather prediction due to the variability and complexity of the physical processes related to rainfall and the need for accurate prediction of other variables it depends on (Stensrud, 2007). Forecasting of rainfall up to $6 \mathrm{~h}$ in advance used to be based on extrapolation techniques or statistical modelling using radar data (Collier, 2007; Sene, 2008). Another traditional approach is based on subjective prediction by a forecaster involving heuristic rules and conceptual models developed from meteorological principles (Collier, 2007; Davis, 2001). All these approaches have serious limitations due to over-simplification of the atmospheric physics and dynamical processes. A more objective way of dealing with this problem is by means of NWP models (Theis et al., 2005; Collier, 2007; Lean et al., 2008; Sene, 2008; Golding, 2009; Warner, 2011; Landman et al., 2012). Uncertainties associated with these NWP systems, however, also need to be taken into account (Sene, 2008).

A major source of uncertainty in NWP models is linked to the requirement to use parameterization schemes for grid resolutions larger than about $4 \mathrm{~km}$ to approximate small subgrid-scale weather phenomena such as convective storms (Stensrud, 2007; Lean et al., 2008; Warner, 2011). These parameterization schemes usually introduce inaccuracies due to their particular inherent approximations that can affect important features of the subgrid-scale convection which impact on forecasts of rainfall in severe thunderstorms. Trigger functions, which determine the activation time and place for convection schemes, also play an important role in the overall forecast design. These uncertainties affect forecasting features of convective precipitation such as onset time, location of convection, duration of rain event and the diurnal cycle of convection (Stensrud, 2007). Typically, Lean et al. (2008) found that the $12 \mathrm{~km}$ resolution version of the Unified Model (UM) from the United Kingdom Met Office tends to initiate convection on average $1-2 \mathrm{~h}$ too early, and tends not to have a realistic shower structure which could lead to an underestimation of rainfall peaks. Additionally, the $12-\mathrm{km}$ UM tends to produce too much light rain and too little heavy rain due to the averaging of rain over a larger grid box, compared to a 1-km UM which simulates convection explicitly.
The problem of location of convection implies that even though the model may correctly predict convection for a region, it may be misplacing the rain relative to where and when it really occurred. This can be a significant problem in a flash flood forecasting scenario where the basins tend to be relatively small (Theis et al., 2005; Sene, 2008).

\section{Obtaining probabilistic rainfall forecasts}

The general approach to address forecast uncertainty in NWP is to obtain probabilistic precipitation forecasts through an Ensemble Prediction System (EPS) (Ebert, 2001; Theis et al., 2005; Toth et al., 2007; Collier, 2007; He et al., 2009; Warner, 2011; Landman et al., 2012). Traditional EPSs involve multiple model runs, which require large computer capacity not readily available in most meteorological services, and far less so in developing countries. A practical solution to this dilemma is obtaining probabilistic rainfall forecasts from a deterministic model pseudo-ensemble system as described by Theis et al. (2005).

In this study the approach to provide a forecast of flash flood potential based on a deterministic model, pseudoensemble prediction system using the $12-\mathrm{km} \mathrm{UM}$, from the United Kingdom Met Office and run at SAWS, is discussed. The supporting modelling systems are discussed in the next section. In the subsequent sections the methodology is described, followed by a discussion of the results through a case study and finally some conclusions.

\section{SUPPORTING MODELLING SYSTEMS AND DATA}

\section{The SAFFG system}

The Central American Flash Flood Guidance system (CAFFG) was introduced in 2004 in Costa Rica for the Central American countries by the HRC based in San Diego, California, USA (Georgakakos, 2005). CAFFG provides FFG, not as a forecast, but as diagnostic information. FFG is defined as the amount of rainfall needed in a basin over a specified time (for example $6 \mathrm{~h}$ ) that could lead to bank full (i.e. water level at the point of overtopping the river banks) at the outlet of the basin. FFG is used by experienced forecasters along with other data, tools and systems to determine the potential for flooding in small basins in the next 1, 3 or $6 \mathrm{~h}$. In 2010 the HRC installed a South African version of CAFFG, the SAFFG system, on request of SAWS and the National Disaster Management Centre (NDMC). SAFFG is a hydrometeorological modelling system similar to CAFFG that covers 5366 small catchments (averaging from 50 to $100 \mathrm{~km}^{2}$ ) around the main metropolitan areas of South Africa, namely, Johannesburg, Durban, Port Elizabeth and Cape Town, as well as the flash flood prone Cape south coast.

Georgakakos (2006) and Ntelekos et al., (2006) describe the modelling concepts applied in the SAFFG in detail, and Sperfslage et al. (2010) provide information on the SAFFG. A short summary will be provided in this section, based on these references. Mean Areal Precipitation (MAP) is accumulated rainfall over the last 1, 3 and $6 \mathrm{~h}$, estimated hourly for each river basin by integrating information from weather radars and the Meteosat Second Generation (MSG) satellite, bias corrected with data from real-time rain-gauges. MAP values are used as precipitation input to the Sacramento soil moisture accounting model to determine the soil moisture deficit of each basin, taking into account relevant basin characteristics such as soil type, vegetation, land-use, slope, etc. Based on the modelled 


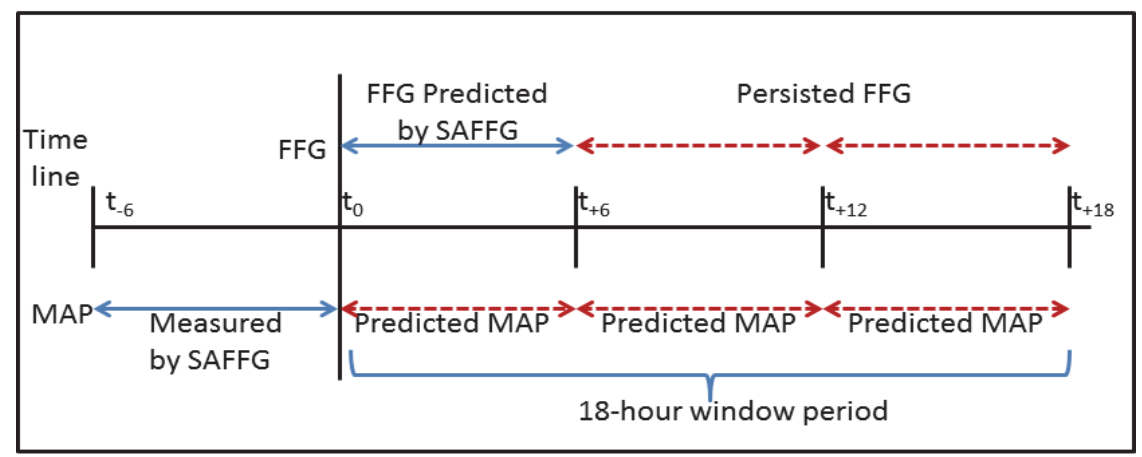

Figure 1

The MAPs for $t+6, t+12$ and $t+18$ are generated from a hybrid ensemble prediction system based on the deterministic UMSA12 model, as explained in the text. The future FFG fields for the next few 6 -h periods beyond time $t+6$ are projected from the initial $t+6$ time period as explained later in the text.

soil moisture fraction, the FFG and Flash Flood Threat (FFT) information is then determined hourly for each of the 5366 small South African river basins as diagnostic information for the following 1, 3 or $6 \mathrm{~h}$. FFT indicates the basins where flash flooding is possible by determining the amount of excess rain for the basin if the basin's MAP is persisted for the next equivalent period, and then comparing this with the FFG value.

In this study MAP values of the SAFFG system were assumed to be 'observations'. This was deemed acceptable in this paper, since the FFG fields of the SAFFG are determined using the same radar/satellite-based MAP values of SAFFG as rainfall 'observations' to calculate soil moisture and ultimately the FFG value. It is against this FFG value that NWP-generated MAP values must be compared to assess flood potential, with both using the same SAFFG basins as common spatial scale.

\section{The Unified Model}

The operational NWP model running in SAWS is the $12-\mathrm{km}$ resolution limited-area version of the UM (UM-SA12) covering southern Africa and extending to the equator. The UM-SA12 is a non-hydrostatic model with a terrain following height-based vertical coordinate system of 38 levels (Davies et al., 2005). It is a grid-point model on a latitude-longitude grid in a limited area model configuration using the same code as its global UM version. Initial values and boundary conditions are supplied by the United Kingdom Met Office global UM. A data assimilation system could also be included to incorporate weather observations to adjust the initial field closer to the 'real world'.

Two configurations of the UM-SA12 were used in this study. Both were running once a day, operationally based on the 00:00 UTC initial field, and ran to $48 \mathrm{~h}$ in advance (Landman et al., 2012). These configurations were:

- Xaana: This version does not incorporate a data assimilation system, and is an early run available by $05: 30$ UTC

- Xaang: This version does have a data assimilation system, and is available by approximately 08:45 UTC to the weather forecasters

The UM-SA12 output data in gridded format for both the xaang and xaana configurations were extracted from the NWP archive of SAWS. The data are archived daily for each model with hourly accumulated predicted rainfall values of up to $48 \mathrm{~h}$ in advance on the $12 \mathrm{~km} \mathrm{x} 12 \mathrm{~km}$ grid.

\section{METHODOLOGY}

The methodology used in this study is based on the basic concepts of deterministic model ensemble prediction as described by Theis et al., (2005), but in the context of the small river basins used in the SAFFG instead of model grid points. A scheme was developed using the UM-SA12 to determine the probability of NWP predicted MAP (UM-MAP) exceeding future FFG values for the SAFFG basins for an 18-h window period.

The first step was to prepare 6-h. accumulated NWP-based rainfall forecasts for each river basin for the entire 18 -h window period. The second step was to determine future FFG fields for the next three 6-h periods $\left(t_{+6}, t_{+12}\right.$ and $t_{+18}$ in Fig. 1$)$ in the $18-\mathrm{h}$ window period, based on information from the SAFFG system. Finally, an outlook of potential flash floods in various basins and in local municipalities (LM) was determined by comparing the probabilistic UM-MAP over the entire 18-h window with its particular future FFG value (see Fig. 1 for a graphical illustration).

\section{Step 1: 18-hour rainfall prediction using the hybrid ensemble prediction system}

The first step required determining a UM-MAP value for every small river basin from the model predicted rainfall data of each of the two different UM-SA12 configurations. These NWP-based UM-MAP values needed to be bias corrected before they could be compared with the SAFFG system's FFG rainfall values. An ensemble prediction system that combines the UM-MAP amounts of the surrounding basins was subsequently developed to predict the probability of precipitation in the basin for the next three 6-h periods.

The hourly precipitation forecasts of the UM-SA12 models, integrated into 6-h totals, were used to calculate a UM-MAP value for each SAFFG river basin over the 18 -h window period. This was done for both available UM-SA12 model configurations, xaana (no data assimilation) and xaang (data assimilation). The basic approach was similar to the approach used in the SAFFG system. A precipitation value at a NWP model grid point represents the average rain at a grid box around the grid point (Warner, 2011) with the size of the model grid box $(12 \mathrm{x}$ $12 \mathrm{~km}$ in the case of the UM-SA12). At a model resolution of $12 \mathrm{~km}$ the small sizes of SAFFG basins made it difficult to find more than even one model grid point in each river basin. This was overcome by interpolating the $12-\mathrm{km}$ grid to a $4-\mathrm{km}$ grid using an equal block approach. This implies that the $4-\mathrm{km}$ grid boxes within an initial $12-\mathrm{km}$ grid box are allocated the same precipitation value as the associated $12-\mathrm{km}$ grid box, but each now represents a $4 \times 4 \mathrm{~km}$ domain. In this way it was possible to calculate UM-MAP values for most SAFFG basins as a simple average from at least four grid boxes of the $4-\mathrm{km}$ resolution grid that resides within the basin. For those few basins that still do not have four associated grid points, the nearest four $4-\mathrm{km}$ grid points were identified using an inverse weight scheme to 


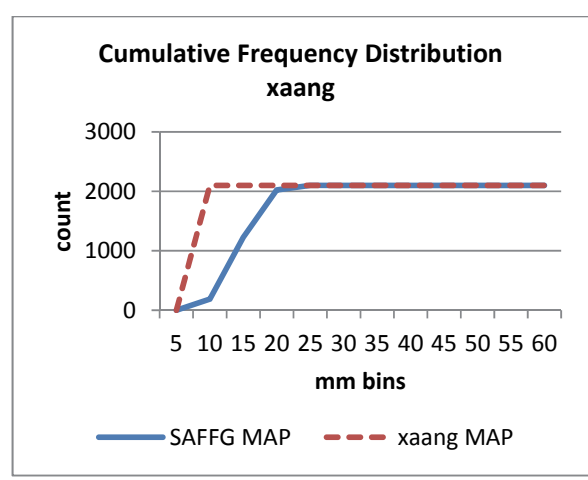

(a)

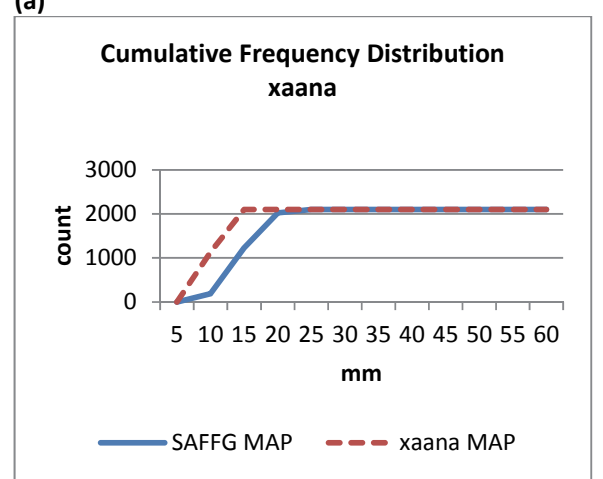

(c)

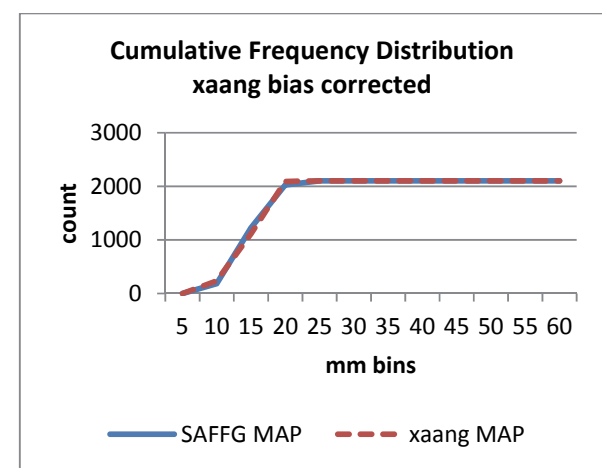

(b)

\section{Cumulative Frequency Distribution} xaana bias corrected

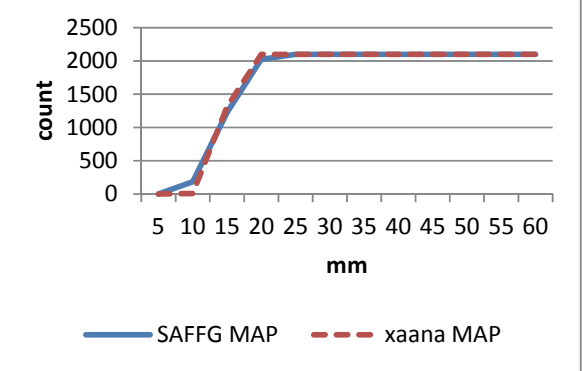

(d) determine their relative contribution to that basin's UM-MAP.

The inability of the UM-SA12 NWP models to predict realistic amounts of rainfall in a basin became evident at an early stage of the study, since the UM-MAP values of the UM-SA12 simulations (xaang and xaana) were significantly lower when compared with the MAP derived from the averaged rainfall observation field of SAFFG. Differences between the two configurations of UM-SA12 (xaana and xaang) were noted due to their different initial fields. Figure 2 illustrates the vast underestimation of 6-h rainfall, averaged over 25 heavy rainfall cases in 2011, for the 2101 basins under the Irene radar domain near Pretoria, compared with the corresponding SAFFG observation MAP values. This emphasized the need for bias correcting each NWP model's UM-MAP to enable fair comparison with FFG values for the same basins from the SAFFG system. A biascorrection factor for each model was determined by:

$$
B C F=\Sigma(\text { MAPum }) / \Sigma(\text { MAPobs })
$$

In Eq. (1) $B C F$ is the bias correction factor, MAPum is the relevant UM-MAP amount, and MAPobs is the corresponding observed SAFFG MAP amount. The sum was calculated over all 2101 basins under the Irene radar, for 25 cases with significant convective rain (days when at least 1 rainfall station reported $50 \mathrm{~mm}$ or more in $24 \mathrm{~h}$ ). For the xaana configuration the $B C F$ was 1.86 and for the xaang configuration $B C F$ was 3.05. The corrective impact of bias correction to the quantity of rainfall is shown in the cumulative frequency distribution graphs in Fig. 2, for both the xaang and xaana configurations of the UM-SA12. The tendency of the $12-\mathrm{km}$ version of the UM in the Lean et al., (2008) experiments to produce too much light rain and too little heavy rain, and the positive corrective impact of bias correction is also clearly illustrated for both model configurations in Fig. 2. The bias correction scheme described above is by no means the optimal scheme, but it does provide a 'climatological' bias correction based on 25 cases that produced heavy rain.

To address the problem of location of convective rainfall, a hybrid EPS as described by Theis et al. (2005) was used in an attempt to capture the uncertainty of both the spatial location and the convection timing challenges, through probabilistic forecasting from the deterministic UM. Theis et al. (2005) identified a 'neighbourhood' of grid points from the same model around the target grid point whose rainfall values could just as well be associated with the target grid point. This grid point approach, however, was replaced in this study by the bias-corrected UM-MAP values of a 'neighbourhood' of SAFFG basins around a target basin. The first reason for this approach was that it allowed the ensemble scheme to calculate probabilistic information on the basic rainfall value used in the SAFFG system, namely, the MAP over a small basin as determined from radar rainfall estimations. Secondly, SAFFG MAP rainfall values were used as 'observations' for the biascorrection scheme as described in the previous section. Lastly, this allowed for a fair comparison between the model ensemble predictions and the FFG basin average values that were generated from these MAP 'observations' in the SAFFG modelling system.

In this hybrid ensemble approach (called HyEPS) the 'neighbourhood' consisted of the 9 closest SAFFG basins identified around each target SAFFG basin (Fig. 3) using a centroid function in the QGIS geographical information system (GIS). In this way the possibility was accommodated that modelpredicted 6-h MAP over any of the 9 neighbouring basins could actually be associated with the target basin due to model error. In addition, the potential offset in timing of the convection by the UM was covered by considering the extended period of $18 \mathrm{~h}$ as a single target outlook window period instead of the operational SAFFG guidance limit of $6 \mathrm{~h}$. The set of ensemble members for each basin thus consisted of 30 bias-corrected 


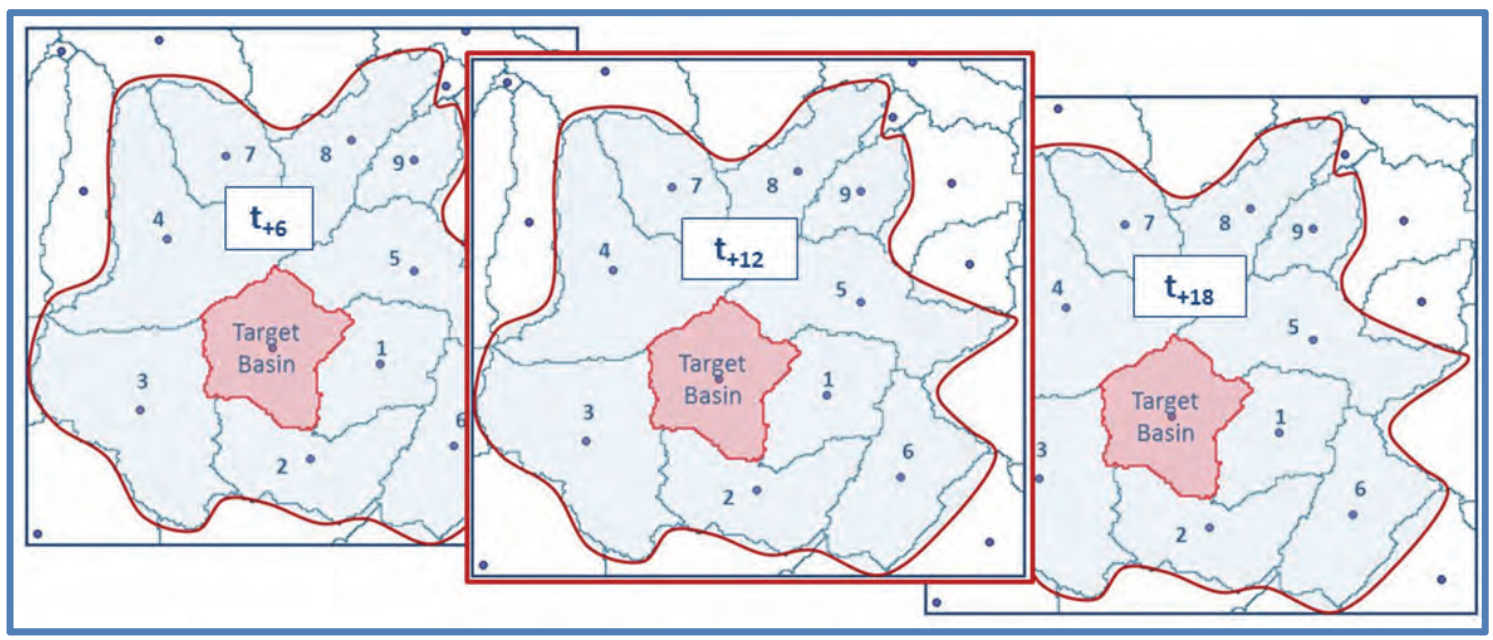

Figure 3

Graphical examples of 10 SAFFG member basins for the $t+12$ NWP forecast period associated with the target basin, and the associated basins of the previous 6 - $h$ period and 6 - $h$ subsequent period. This provides, in total, 30 HyEPS members for the target basin over $18 \mathrm{~h}$.

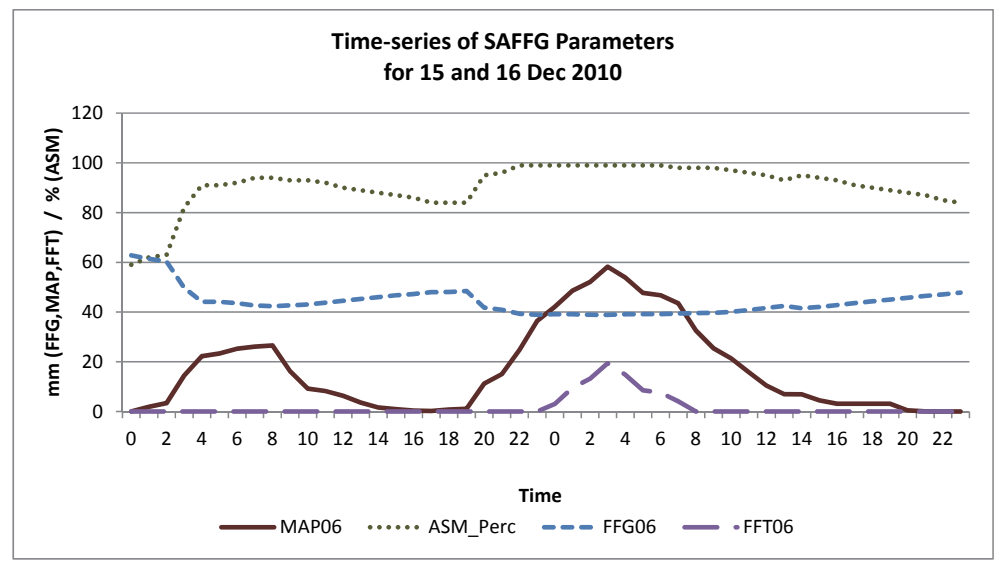

Figure 4

A graphical representation of the four main parameters of the SAFFG as they evolved during the flash flood event of 15 and 16 December 2010 in a specific basin in the Dipaleseng Local Municipality. MAP06 is the 6-h accumulated MAP as determined by SAFFG from radar data; $A S M \_$Perc is the top layer soil moisture percentage saturation; FFG06 is the 6- $h$ flash flood guidance; and FFT06 is the 6- $h$ flash flood threat if the MAP06 of the previous $6 \mathrm{~h}$ is persisted for the subsequent $6 h$.
UM-MAP values from the 30 basins in its neighbourhood covering a period of $18 \mathrm{~h}$ (Fig. 3).

\section{Step 2: Projecting Flash Flood Guidance (FFG) information to the next 18 hours}

An important requirement to enable a prediction of flash flood potential in the next 18 -h window period is the need to determine future FFG fields for the next three 6-h periods based on information from the SAFFG system. These FFG values are needed for comparison with the HyEPS UM-MAP forecasts in order to identify which basins could receive more rain than required for bank full at the basin outlet and thus have a potential for flash flooding in the next $18 \mathrm{~h}$. To achieve this, soil moisture deficit and then the FFG for future 6-h periods need to be modelled based on the previous 6-h UM-SA12 predicted MAP. In the current configuration of the SAFFG modelling system available for this study, however, it is not possible to predict FFG values beyond $6 \mathrm{~h}$ into the future. Although this is the ideal situation, it will require a substantial change to the hydrological modelling system to incorporate NWP rainfall forecasts to do so.

Consequently, the only other approach is to extrapolate, or persist, the latest available 6-h FFG values in 6-h periods, up to $18 \mathrm{~h}$ in advance, as shown in Fig. 1. This approach assumes that the soil moisture content, and thus the FFG values in the basins, should not change significantly in the subsequent $12 \mathrm{~h}$. Clearly, this assumption cannot be completely true, particularly if significant rain fell which could lead to saturation of the top soil and reducing FFG values. An analysis of the response of soil moisture and FFG values from the SAFFG system during different rainy conditions, however, provided confidence that this assumption could be deemed acceptable for this limited additional period, taking into account the modelling limitations just mentioned.

As a typical example, the main relevant parameters in the SAFFG that evolved in hourly intervals during a flash flooding situation in a SAFFG basin south of Johannesburg, on 15 and 16 December 2010, are provided in Fig. 4. The response of the SAFFG soil moisture saturation (ASM in Fig. 4) and FFG parameters to the heavy rain (MAP) is quite evident for both the first rain episode that occurred between 02:00 and 10:00 UTC on the $15^{\text {th }}$, and the second rain episode that occurred from 08:00 UTC on the $15^{\text {th }}$ to about 14:00 UTC on the $16^{\text {th }}$. The soil moisture saturation level (ASM) jumped from $60 \%$ to about $90 \%$, settled slowly and then jumped from $85 \%$ to $100 \%$ where it stayed for a while before settling slowly again. The FFG was already at about $60 \mathrm{~mm}$ and dropped with the first rain episode to just over $40 \mathrm{~mm}$ accumulated in 6 -h over the 


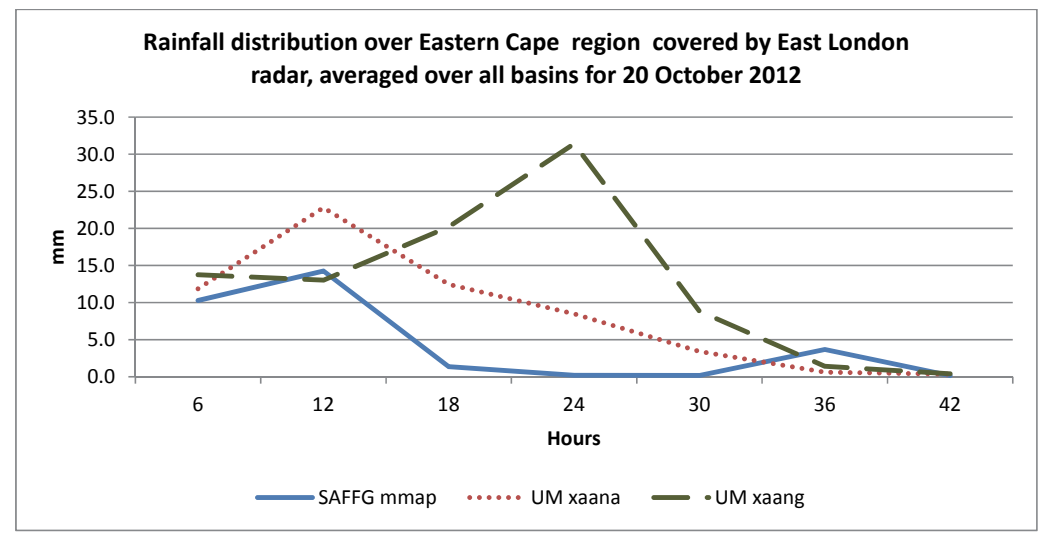

Figure 5

The rainfall distribution averaged over all the basins in the East London radar region of the Eastern Cape Province of South Africa on 20 October 2012. The solid line is the observations as represented by SAFFG MAP. The dotted line is the rainfall forecast from the xaana configuration of the UM-SA12 initiated at 00:00 UTC and the dashed line the associated UM-SA12 forecasts using the xaang configuration. basin for potential flash flooding at its outlet. Again it settled slowly to about $50 \mathrm{~mm}$ before it dropped again with the second episode to about $39 \mathrm{~mm}$. Whenever the rainfall reduced or stopped the FFG rose slowly.

If the FFG was persisted, on the one hand, at its level of 48 $\mathrm{mm}$ on 18:00 UTC on the $15^{\text {th }}$, for the next $12 \mathrm{~h}$, it would have been too high at midnight when the actual values dropped to $39 \mathrm{~mm}$ due to the rain that fell between 18:00 UTC and 00:00 UTC. Thus, by keeping the FFG at a previous level, in a period when more rain is expected, a conservative estimate of potential flooding is created since the FFG is likely to drop due to the rain. On the other hand, if the FFG at 00:00 UTC was persisted at its value of $39 \mathrm{~mm}$ for the next $12 \mathrm{~h}$, it would have been too low compared to the actual FFG, which was slowly declining to higher values. But, then, FFG rose in this situation because no rain fell and the flash flood threat disappeared. Lastly, this case was a real extreme rainfall case where $133 \mathrm{~mm}$ of rain fell in that area between 18:00 UTC on the $15^{\text {th }}$ and 06:00 UTC on the $16^{\text {th }}$. Yet the basins still responded relatively slowly over the next $12 \mathrm{~h}$ compared to rain episodes, particularly when the rain stops.

From this discussion, it is assumed that a reasonable approach is to persist the FFG values for the next few periods in the absence of a capability to model its future values. An outlook of potential flash flooding can then be regarded as a conservative estimate, which could lead to some missed events, but should not lead to false alarms.

\section{Step 3: Flash flood outlook products from the hybrid ensemble system}

Various products were generated from this HyEPS 30-member ensemble set representing the 18 -h window period. The most important of these was the Flash Flood Potential (FFP) of each basin over the 18-h window period, calculated as the probability of the basin ensemble UM-MAP values (or the percentage of members) exceeding the representative FFG values of the basin for the same 18-h window period. Another useful product was the flash flood hazard index for a local municipality (LM-FFH), which was determined as the percentage of SAFFG basins within a local municipality with a positive FFP. For comparison this was done for both the xaang and xaana configurations of the UM-SA12 model.

\section{CASE STUDY: THE PORT ALFRED FLASH FLOOD EVENT}

Flash flood events are by nature extreme events that do not occur that often. In the 24-month period for which
SAFFG-archived data was available to this study, only a small number of significant events occurred within the SAFFG domain. A prominent event, for example, occurred on 20 October 2012 when a cut-off low-pressure system caused heavy rain and flash flooding over the Eastern Cape Province of South Africa. The two UM-SA12 configurations differed in their precipitation forecasts for this event and therefore it provides an excellent opportunity to test the concepts of HyEPS.

Significant damage was caused to infrastructure and homes near Port Alfred where people were forced to leave their homes due to flooding. Houses of 57 residents in the nearby informal settlement were damaged and hundreds of residents were without water or electricity (SAWS, 2012). Cars were submerged and some houses were flooded with up to $2 \mathrm{~m}$ of water. A bridge was washed away and the damage to infrastructure and cars was estimated to be more than R1 billion. The N2 national road between Port Elizabeth and Grahamstown was washed away at a gully outside Grahamstown resulting in road closure and severely disrupting traffic.

\section{Simulating the rainfall outlook through HyEPS}

The rainfall patterns as shown roughly by the MAP rainfall averaged distributions over the domain in Fig. 5 were reasonably well predicted by the $20^{\text {th }}$ 00:00 UTC run using the xaana configuration of the UM-SA12, although it underestimated the amount of rain that fell $12 \mathrm{~h}$ later near Port Alfred. The xaang configuration of the UM-SA12 predicted much more rain, but misplaced the peak amounts to occur between 18:00 UTC and midnight on the $20^{\text {th }}$. These two runs therefore provide the opportunity for an interesting comparison of the application of the deterministic model pseudo-ensemble system by two different model forecasts for the same event.

For each basin, the 6-h rainfall measured by SAFFG MAP has been averaged for the three 6-h periods within the relevant 18-h window period. A comparison of the averaged rainfall for the $0-18$ and 6-24 18-h window periods is provided (Fig. 6). The model average is the average of all 30 ensemble members (each $6 \mathrm{~h}$ in duration) relevant to the particular basin and covering the same 18 -h window period, done for xaang and xaana configurations respectively. It is quite evident that the UM-SA12 with the xaang configuration did not capture the average rain positioning correctly as compared with the SAFFG MAP average on the left hand side of Fig. 6 for both periods. This was mostly due to the mistiming of the rainfall generated by the xaang configuration as the rainfall moved southeast out over the ocean. The UM-SA12 with the xaana configuration, however, performed 


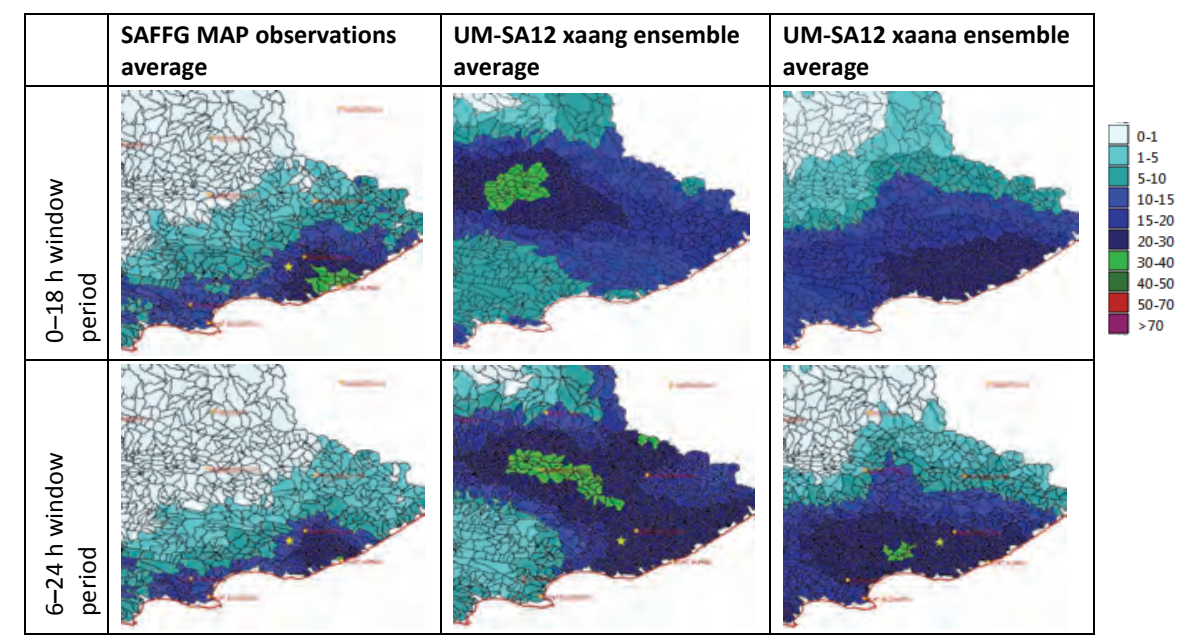

Figure 6

Comparison of the 6- $h$ SAFFG MAP average rainfall observations over the relevant 18-h window periods with the average ensemble forecasts of the UM-SA12 xaang and xaana configurations, respectively, for the same periods on 20 October 2012.

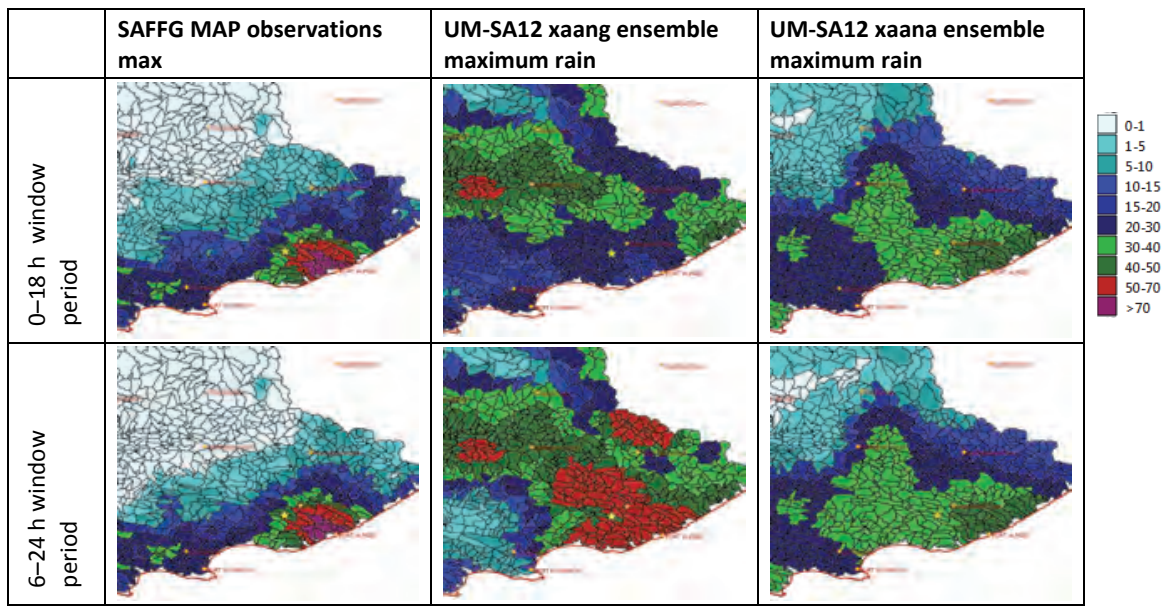

Figure 7

Comparison of the 6-h SAFFG MAP maximum rainfall observations over the relevant 18-h window periods with the maximum ensemble forecasts of the UM-SA12 xaang and xaana configurations, respectively, for the same periods on 20 October 2012.

better in capturing the timing, although the total amounts were a bit low.

The main purpose of this case study was to determine the potential for flash flooding in small river basins from NWP forecasts. Consequently, the most important product was the FFP of each basin over the 18 -h window period calculated as the probability of the basin ensemble UM-MAP values (or the percentage of members) exceeding the representative FFG values of the basin for the same 18 -h window period. This implies that the members with the highest values for each basin will be important to identify, since they have the best chance of exceeding the FFG value of the basin. A chart with the highest rainfall value of all ensemble members for a particular basin is a simple representation of this methodology from a rainfall perspective. Figure 7 shows rainfall maps of the maximum 6-h rainfall value from all 30 ensemble members for each basin for the two 18-h window periods under discussion using the two model configurations. The SAFFG MAP observation maximum was just the highest of the 3 relevant observed 6-h periods for the basin. Again the xaang model configuration overestimated the rainfall in the wrong areas, although the xaang configuration's $6-24 \mathrm{~h}$ window period provided quite good forecasts for the areas that did receive the highest rainfall in this period around Port Alfred. The xaana model configuration performed much better with the highest values in the Port Alfred area, though much lower values than experienced.
Verification metrics were calculated for both the ensemble average and the ensemble maximum rainfall fields of the UM-SA 12 forecasts using the xaana and xaang configurations compared to the observed SAFFG MAP fields for the two 18-h window periods. The domain covered is the same as in the images in Fig. 7 and involved 432 small river basins. A contingency table was prepared for each forecast determining event 'hits', 'false alarms', 'misses' and 'correct non-events'. These data were used to calculate a variety of scores including the Critical Success Index (CSI), Hanssen-Kuipers Score (KSS) and Heidke Skill Score (HSS) (Wilks, 2006; Jollife and Stephenson, 2012). These three scores were identified since they measure attributes of 'accuracy' (the level of agreement between forecasts and observations, measured by CSI), 'skill' (accuracy of forecast compared to the accuracy of being correct by chance, measured by HSS) and 'discrimination' (ability of forecasts to distinguish between occurrences and non-occurrences of the event, measure by KSS).

Figure 8 depicts a graphical illustration of the verification results. From all three indicators it is evident that the xaana configuration of the UM-SA12 performed the best. The xaang configuration performed the worst, with the $0-18 \mathrm{~h}$ forecast actually misleading, particularly for the higher thresholds beyond $15 \mathrm{~mm}$. This applied for all three attributes of accuracy, skill and discrimination. The xaang configuration 6-24 h forecast performed better at higher thresholds than lower thresholds for skill and discrimination as measured by 


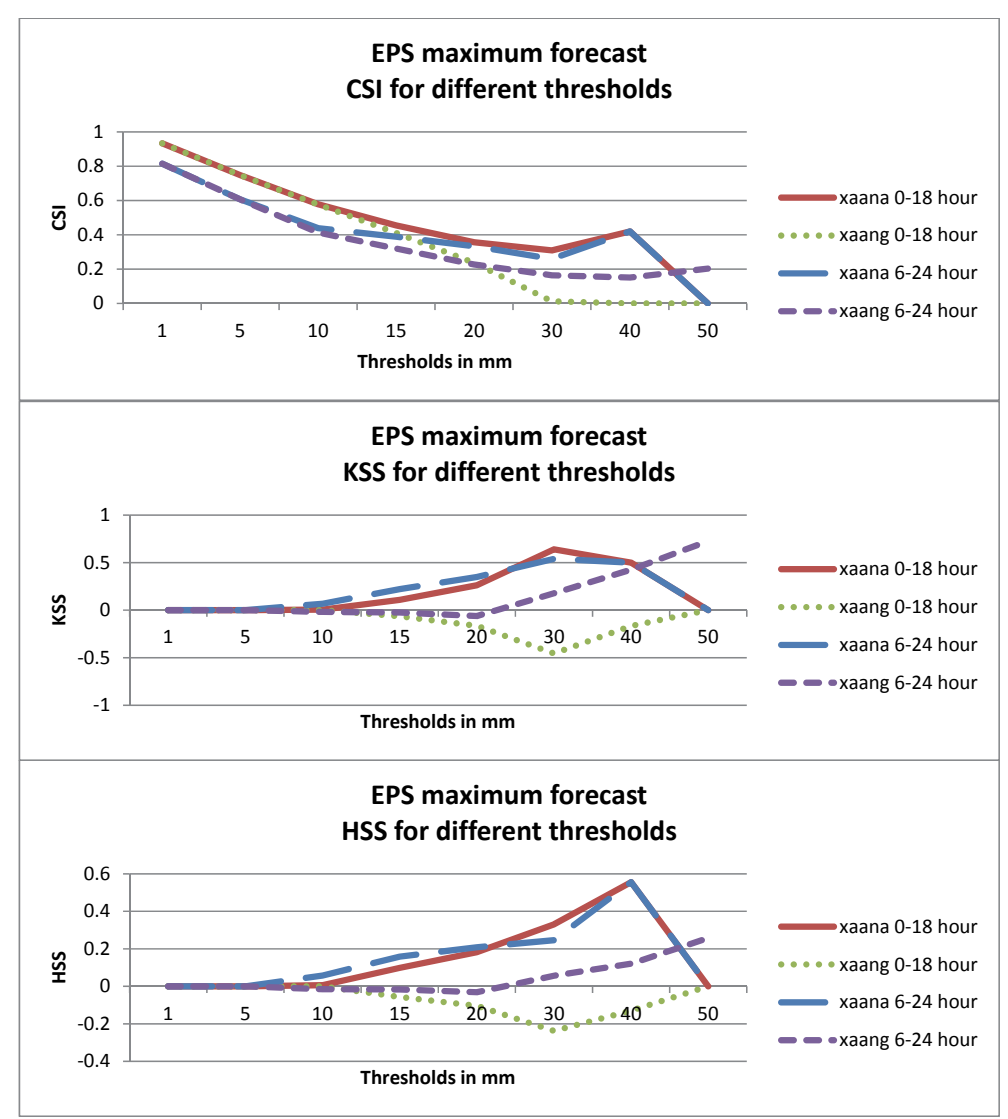

Figure 8

Verification statistic for the EPS maximum forecasts for the UM -SA12 xaana and xaang configurations for the 0-18 and the 6-24 $\mathrm{h}$ window periods for different rainfall thresholds on 20 October 2012. The top panel shows the CSI, the middle panel the KSS and the bottom panel the HSS.

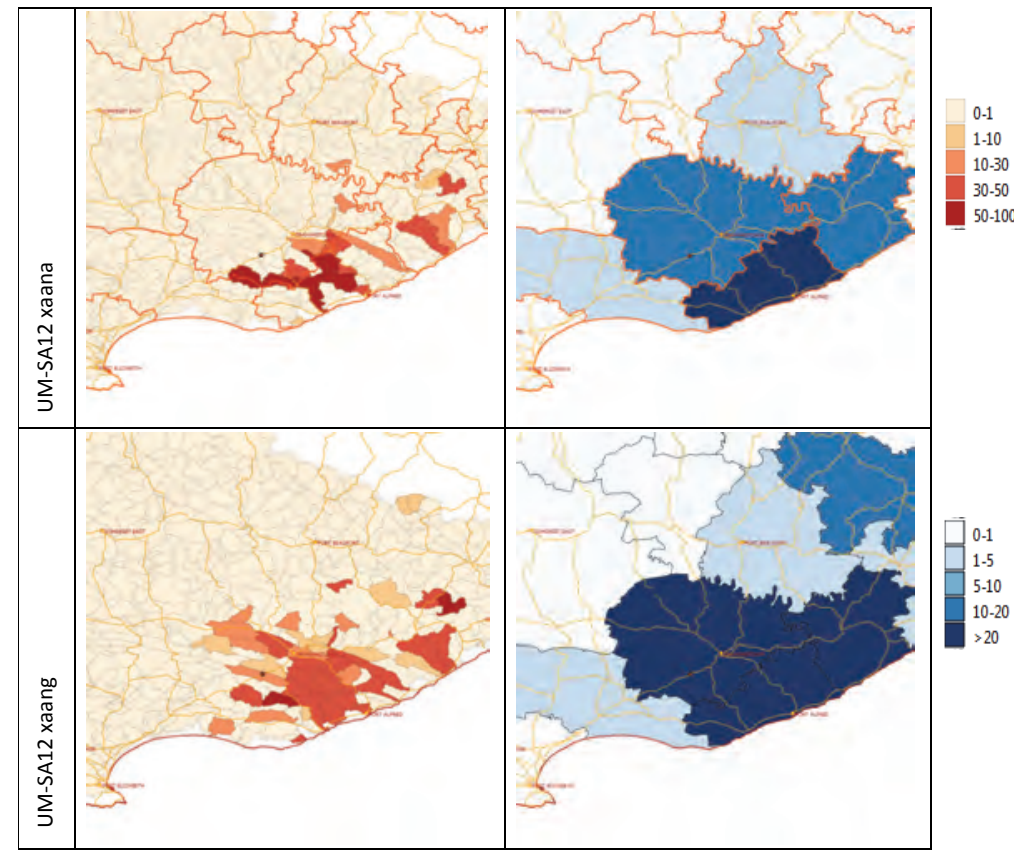

Figure 9

6-24 h FFP (left) and LM-FFH (right) fields of the UM-SA12 xaana and xaang configurations of 20 October 2012 00:00 UTC based on the 12:00 UTC FFG. the Heidke Skill Score and the Hanssen-Kuipers Scores, respectively. Consequently, though the UM-SA 12 forecasts for the 18-h forecast window were not exactly correct, the xaana configuration produced useful forecasts, with the xaang 6-24 h showing some skill above chance and ability to discriminate between occurrences and non-occurrences at the higher thresholds. Thus, the HyEPS ensemble rainfall forecasts provided useful outlooks for the rainfall over the two 18-h window periods in this particular case study.

\section{The 18-hour flash flood outlook}

The probabilistic FFP values for the case study of 20 October 2012 are presented in Fig. 9 (left panels) of both the xaana and xaang configurations of the UM-SA 12 for the 6-24 h window period. FFP was calculated as the percentage of ensemble members that would have exceeded the persisted 12:00 UTC FFG value for the particular basin. The right-hand panels (LM-FFH) in Fig. 9 indicate the number of SAFFG basins in the FFP products that show an outlook of potential flooding in a local municipality compared to all the basins of the particular local municipality, and is aimed purely as a 'heads up' of likely adverse conditions.

Based on the HyEPS forecasts, both the xaana and xaang configurations of UM-SA12 identified by 12:00 UTC the Ndlambe local municipality (which includes the town of Port Alfred) to have a high likelihood of potential flash flooding in the 6-24 $\mathrm{h}$ window period. Both model runs also forecast a higher FFP potential in the Kowie River running into Port Alfred, with the xaana configuration indicating more than $66 \%$ of the members expected more rain than required for potential flash flooding in this basin during this period. The LM-FFH and FFP thus accurately provided an early outlook of the flash flooding in Port Alfred that occurred later that day. As a reference, the SAFFG system in hindsight identified that the same basins would have flooded given the rainfall as estimated from the East London radar.

\section{RESULTS}

Based on the HyEPS forecasts, the UM-SA12, with both the xaana and xaang configurations, was able to identify potential flash flooding in the 6-24 heriod using the persisted $12-\mathrm{h}$ FFG values for the case study of 20 October 2012. This suggests that the forecast rain from a deterministic NWP model can provide useful information of potential future rainfall patterns at the small basin scale if used in a hybrid EPS as described in this paper. The xaana configuration of the UM-SA12, which does not incorporate a data assimilation system, performed better in this case study than the xaang configuration of UM-SA12 which does incorporate a data assimilation system. In other case studies (not 
discussed in this paper) the xaang configuration, however, performed better than the xaana configuration of UM-SA12. No clear preference could be identified for the data assimilation configuration or the non-data assimilation configuration of the UM-SA 12 to predict rainfall probability in small river basins through the HyEPS.

Through the HyEPS ensemble approach, the uncertainties associated with NWP rainfall forecasts could be addressed, particularly regarding location and onset-time of convective rainfall (Stensrud, 2007; Lean et al., 2008). The HyEPS also performed better for the 20 October 2012 case study than the individual deterministic model forecasts that the HyEPS was based on. Similar results were found for other case studies which are not discussed in this paper. This result confirms the value of an EPS approach to address the uncertainties of NWP related to rainfall forecasts, even if that EPS approach needs to be applied to a deterministic model (Theis et al., 2005).

A major limitation of the approach followed in this paper is the assumption that the FFG values can be persisted for another 12 or $18 \mathrm{~h}$. How valid was this assumption in the case study of 20 October 2012? The real-time FFG from the SAFFG archive was lower than the HyEPS maximum rainfall for the xaana configuration of UM-SA12 for the basins in the Kowie River just upstream of Port Alfred between 04:00 UTC and 23:00 UTC. Consequently, these basins would have had a potential for flash flooding in the Kowie River flowing into Port Alfred between those hours based on the HyEPS rainfall forecast already available early in the morning. For this case study the assumption of persisting the FFG is thus valid.

The combination of the expected rainfall from the HyEPS with persisted FFG values demonstrated the ability of the ensemble approach to extend the lead-time of the SAFFG system from the original 6-h to provide an outlook of potential flash flooding 18 or $24 \mathrm{~h}$ into the future. The flash flood outlook products based on the combination of HyEPS with persisted FFG values, namely FFP and LM-FFH, identify potential future flash flooding in small river basins for the extended lead-time of 18 or $24 \mathrm{~h}$. These outlook products thus can be used to draw the attention of forecasters and disaster managers to the likelihood of flash flooding, and can play an important role in supporting the decision making processes of forecasters and disaster managers.

\section{CONCLUSIONS AND RECOMMENDATIONS}

Disaster managers require more lead-time than $6 \mathrm{~h}$ to prepare and react appropriately to threatening disasters. The SAFFG system currently provides at most a 6-h nowcast based on persisting the previous 6 -h rainfall into the coming 6 -h period, which is most times not an appropriate assumption. NWP provides the most appropriate means of addressing the forecast of rainfall for the next $24 \mathrm{~h}$, but uncertainties associated with rainfall forecasts by NWP are a serious limiting factor.

In response to the need for additional lead-time, the ultimate objective of this study was to provide an outlook of potential flash flooding over the next 12 to $18 \mathrm{~h}$ beyond the initial 6-h nowcast of the SAFFG system. This was dealt with by using UM-SA12 NWP rainfall forecasts for an 18-h window period in an ensemble mode. A high-resolution EPS running a number of ensemble members is the most appropriate approach required (Ebert, 2001; Theis et al., 2005; Landman et al., 2012). Unfortunately, few developing countries using the FFG technology can afford the computer resources to run such an EPS. In the absence of such a traditional EPS the HyEPS deterministic model EPS, based on the work of Theis et al. (2005), was developed and applied to the small river basins. A description of the methodology has been presented. This low-cost post-processing system provided the ability to calculate a set of 30 ensemble members for each small basin from a single deterministic NWP model.

The computations described in this paper used the precipitation forecast output products of a single model and can be done on typical desktop computers. Hence, this methodology is quite suitable to be applied in smaller weather services, even those not running their own NWP model but that have access to the gridded rainfall output of a model run at a regional or global weather centre.

One of the biggest challenges to the proposed approach is the requirement to persist the FFG values of the river basins over the 18 -h period. A better approach would be to use the model rainfall forecasts in the SAFFG modelling system to determine the future soil moisture and FFG values dynamically. This would require, however, a modification to the FFG modelling system. Until that can be done the persisted FFG values over the $18 \mathrm{~h}$ provide a next-best option. Different scenarios could be developed where the FFG values could be dropped by $10 \%$ or $20 \%$ in anticipation of the impact of expected rain on the soil moisture.

The flash flood outlook is provided through two products developed in this study that will be available to the forecasters and disaster managers. The first product is the LM-FFH, or flash flood hazard map for local municipalities based on the percentage of small basins in the municipality with a positive indication of potential flash flooding. This product provides a 'heads up' to a local municipality where potential hazardous flash flooding can occur and is aimed to draw the attention of disaster managers or forecasters to a possible problem area. Having drawn this attention the user then could access the FFP product to get more detail of the location and extent of the potential hazardous situation. The FFP, or flash flood potential, provides a probabilistic outlook for the next $18 \mathrm{~h}$ of the likelihood of potential flash floods in small river basins, based on the rainfall ensemble forecast. From then on, as time passes, the situation can be monitored using the regular SAFFG products and other information. Typically the LM-FFH and FFP products should be part of an early warning dashboard in a forecasting office and a disaster management centre.

\section{ACKNOWLEDGEMENTS}

The SAWS and the Water Research Commission (WRC) provided funding for this work.

\section{REFERENCES}

AMS (AMERICAN METEOROLOGICAL SOCIETY) (2012) American Meteorological Society Glossary of Meteorology. URL: http:// amsglossary.allenpress.com/glossary (Accessed 1 July 2013).

AULD H (2008) Disaster risk reduction under current and changing climate conditions. WMO Bull. 57 (2) 118-125.

COLLIER CG (2007) Flash flood forecasting: what are the limits of predictability? Q. J. R. Meteorol. Soc 133 3-23.

CRED (2014) Centre for Research on the Epidemiology of Disasters International Disaster Database, Université Catholique de Louvain, Brussels, Belgium. URL: http://www.cred.be/ (Accessed 4 February 2014).

DAVIES T, CULLEN MJP, MALCOLM AJ, MAWSON MH, STANIFORTH A, WHITE AA and WOOD N (2005) A new dynamical core for the Met Office's global and regional modelling of the atmosphere. Q. J. R. Meteorol. Soc. 131 1759-1782. 
DAVIS RS (2001) Flash flood forecast and detection methods. AMS Meteorol. Monogr. 28 (50) 481-526.

EBERT EE (2001) Ability of a poor man's ensemble to predict the probability and distribution of precipitation. Mon. Weather Rev. 129 2461-2480.

GEORGAKAKOS KP (2005) Modern operational flash flood warning systems based on flash flood guidance theory: Performance evaluation. In: Proceedings of the International Conference on Innovation, Advances and Implementation of Flood Forecasting Technology, 9-13 Oct 2005, Bergen-Tromso.

GEORGAKAKOS KP (2006) Analytical results for operational flash flood guidance. J. Hydrol. 317 81-103.

GOLDING BW (2009) Uncertainty propagation in a London flood simulation. J. Flood Risk Manage. 2 2-15

HE Y, WETTERHALL F, CLOKE HL, PAPPENBERGER F, WILSON M, FREER J and McGREGOR G (2009) Tracking the uncertainty in flood alerts driven by grand ensemble weather predictions. Meteorol. Appl. 16 91-101.

IPCC (INTERGOVERNMENTAL PANEL ON CLIMATE CHANGE) (2012) Managing the risks of extreme events and disasters to advance climate change adaptation. In: Field CB, Barros V, Stocker TF, Qin D, Dokken DJ, Ebi KL, Mastrandrea MD, Mach KJ, Plattner GK, Allen SK, Tignor M and Midgley PM (eds) A Special Report of Working Groups I and II of the Intergovernmental Panel on Climate Change. Cambridge University Press, Cambridge.

ISDR (2005a) Living with Risk: A Global Review of Disaster Reduction Initiatives. ISDR, Geneva.

ISDR (2005b) Hyogo Framework of Action 2005 - 2015: Building the resilience of nations and communities to disasters. Final report to the World Conference on Disaster Reduction. ISDR, Geneva.

JOLLIFFE IT and STEPHENSON DB (2012) Forecast VerificationA Practitioner's Guide in Atmospheric Sciences ( $2^{\text {nd }}$ edn.). WileyBlackwell, Chichester. 274 pp.

LANDMAN S, ENGELBRECHT FA, ENGELBRECHT CJ, DYSON LL and LANDMAN WA (2012) A short-range weather prediction system for South Africa based on a multi-model approach. Water SA 38 765-773.

LEAN HW, CLARK PA, DIXON M, ROBERTS NG, FITCH A, FORBES R and HALLIWELL C (2008) Characteristics of highresolution versions of the Met Office unified model for forecasting convection over the United Kingdom. Mon. Weather Rev. 136 3408-3424.

NTELEKOS AA, GEORGAKAKOS KP and KRAJEWSKI WF (2006) On the uncertainties of flash flood guidance: towards probabilistic forecasting of flash floods. J. Hydrometeorol. 7 896-915.

PARRY M, CANZIANI O and PALUTIKOF J (2008) Key IPCC conclusions on climate change impacts and adaptations. WMO Bull. 57 (2) $78-85$.

PELLING M (2011) Adaptation to Climate Change - from Resilience to Transformation. Routledge, New York. 203 pp.

POOLMAN ER (2009) Analysis of DMA questionnaires from 2009 SAFFG workshops. SAFFG Internal Report SAFFG-Gen-007.1. South African Weather Service, Pretoria

SAWS (2012) Climate Summary for South Africa: October 2012. SAWS Clim. Summ. 2310.

SENE K (2008) Flood Warning, Forecasting and Emergency Response. Springer Science and Business Media, New York. 303 pp.

SPERFSLAGE J, SPENCER C and GEORGAKAKOS K (2010) South African Flash Flood Guidance System User's Guide. HRC Limited Distribution Report No. 32. Hydrologic Research Centre, San Diego. 210 pp.

STENSRUD DJ (2007) Parameterization Schemes: Keys to Understanding Numerical Weather Prediction Models. Cambridge University Press, Cambridge. 459 pp.

THEIS SE, HENSE A and DAMRATH U (2005) Probabilistic precipitation forecasts from a deterministic model: a pragmatic approach. Meteorol. Appl. 12 257-268.

TOTH Z, SCHULTZ P, MULLEN S, DEMARGNE J and ZHU Y (2007) Completing the forecast: assessing and communicating forecast uncertainty. In: ECMWF Workshop on Ensemble Prediction. 7-9 November 2007, Reading.

WARNER TT (2011) Numerical Weather and Climate Prediction. Cambridge University Press, New York. 526 pp.

WILKS DS (2006) Statistical Methods in the Atmospheric Sciences ( $2^{\text {nd }}$ edn.). Academic Press, Amsterdam. 627 pp.

WMO (WORLD METEOROLOGICAL ORGANISATION) (2008) Guide to Hydrological Practices, Vol II. WMO, Geneva.

WMO (WORLD METEOROLOGICAL ORGANISATION) (2011) Manual on Flood Forecasting and Warning. WMO No. 1072. WMO, Geneva. 